\title{
Information Acquisition and Social Media: An Analysis of Pakistani University Students
}

\author{
Iffat Ali $A^{*}$ and Zahid Yousaf
}

Centre for Media and Communication Studies, University of Gujrat, Gujrat, Pakistan

\begin{abstract}
As social media becomes increasingly ubiquitous, organizations are looking for the best way to use these new communication tools. Social media sites like Facebook and Twitter present numerous opportunities to organizations for sharing information, engaging with the public, and monitoring discussion. The current study aimed to explore the use of social media for news acquisition which come under cognitive needs. A survey was conducted involving Pakistani university students by indicating their qualification, gender, area, usage patterns, time spent and their information seeking interests. The need for information was divided into hard and soft news and the results indicated youth heavier users of social media for information regarding current issues particularly local news. The social media is used for information regarding hard news and soft news both and findings highlighted trends for using social media for information acquisition. The news values for social media are also pivotal, majority of respondents showed their concerned for local news i-e proximity. The other factor which accelerates frequency of usage is information during crisis situation. The News about calamity and relief work was searched more on social media as latest updates and instant feedback were available there. In social media, Facebook is mostly used social networking site. The demographics such as background, qualification, gender and area were also found influential factors for using social media for news.
\end{abstract}

Keywords: Social media; News preference; Social media usage; Social media news consumption

\section{Introduction}

The information flow through traditional and later through social media barred all the hindrances and easy access to information sources diminishing difference between have and have not. But in this situation, where media is used for multiple needs, suppressed the core function of media, i-e dissemination of information. Therefore, this study was designed to record the use of social and 1 media for information seeking purposes among youth. In Pakistan out of total population 190 million, youth constitute $63 \%$ of total population that is why mostly media studies include youth as sample to know major trend and penetration of media. For information, widely used source is media, either traditional (TV, Radio, Newspaper) or social media (Facebook, Twitter, YouTube). But vivid evidence is available and supported a shift from traditional to social media [1] for multiple reasons such as easy access, mobility, visual sharing and feedback. Simply posting information and updating people with latest happening is no more significant in social media era. The social media revolution has taken far ahead from active audience as described in Uses and Gratification theory. Now the audiences select information according to their interest and needs and believe in which they can contribute into content and share their opinions. Therefore, the technology convergence helped dying news sources and alive them again through news media like e-versions of newspapers, radio podcasts, online TV etc. Similarly the role of state fourth pillar is being undermined by new media [2].

\section{Problem Statement}

Across glob various studies had found excessive use of social media among students [3]. Initially social media was found a vehicle for socialization and communication. But later social media drastically dominated news domain [4]. Similarly in Pakistan, the gradual use of social media for news is growing, particularly after using the social media for political mobilization. Youth and university students were found heavier user of social media, therefore, this study aimed to explore preference of media by youth for news purposes. This study would be a baseline to establish the role of social media as fifth state pillar in Pakistan.

\section{Objectives of the Study}

The study was intended for following objectives:

- To find out the use of social media for news seeking

- To describe how social media changed news consumption pattern among university students

- To record how much time they spent on social media for news purposes

- To explore how gender and education influence the news seeking pattern through social media

- To investigate role for social media to make youth more or less informed on current issues

- To probe the situation in which need for information acquisition increase at social media.

\section{Literature Review}

The "Global Village" phenomena is all around and bestowing people with choices of information and they can select any source of

*Corresponding author: Iffat Ali A, Assistant Professor, Centre for Media and Communication Studies, University of Gujrat, Gujrat, Pakistan, Tel: 0310-5855809; E-mail: iffat@szabist-isb.edu.pk

Received September 27, 2017; Accepted October 06, 2017; Published October 09, 2017

Citation: Iffat Ali A, Yousaf Z (2017) Information Acquisition and Social Media: An Analysis of Pakistani University Students. J Mass Communicat Journalism 7: 350 doi: 10.4172/2165-7912.1000350

Copyright: ( 2017 Iffat Ali A, et al. This is an open-access article distributed under the terms of the Creative Commons Attribution License, which permits unrestricted use, distribution, and reproduction in any medium, provided the original author and source are credited. 
information even through multiple sources, they can verify information. The previous studies have demonstrated that selection of medium for information is influenced by factor such as gender, age, education and location. Therefore, numerous studies explored selection of media for informational purposes with varied demographics and people from different backgrounds. The Americans are the extensive users of local TV news for breaking news, and traffic situation. But it is not the only preferred source of information, particularly the youth is no longer using TV much as a news medium, is posing serious concerns for the long-term future of this medium. The same threat is posed at newspaper; one reason is the non-existence of local newspapers. The availability of other sources such as local radio, local TV and above all social media gaining more attention for local news and information. The survey by YouGov found that almost $51 \%$ percent of the people are using social media to get their news and information on daily basis. Although a nominal but significant $12 \%$ users regarded it as most consumed source. In social media research, Facebook ranked highest in news consumption and socialization domain. The same survey indicated that Facebook was prime source of information and news for 18 years to 24 years of people.

Andrew and Jason investigated the behavior and preferences of people for choosing digital news, found older generations preferred traditional media for news which is due to their lack of interaction with technologies. Due to familiarity of youth with technologies resulted in extensive use of social media and dominance of youth on social networking sites is evidence for growing usage of social media in youth. The gender is an important factor for selection of media and it is described by earlier conducted studies. Male and female have different reasons for using SNS. Hargittai [5] found that women spend more time on SNS as compared to men. Stafford said that men use SNS like Facebook to socialize and create new relationships whereas women use it to get connected to friends, for fun and to make best use of their free time. Raacke and Bond observed that change in social networking account is more frequent in women as compared to men.

\section{News acquisition through social media}

Initially, the major source of national and international news was Television but in underdeveloped countries radio is prime source of news. People in some countries depend more on television as mean of gaining news, in Indonesia this percentage is $99 \%$ while in Malaysia for $97 \%$ people TV remains the main source for news, same is the case in Venezuela and Turkey where television has its primary importance for broadcasting news to maximum people. Now the internet is a significant source of information all across the world with its limitation such as access and knowledge. Particularly in developing countries where access of online technology is limited, online news is less popular.

In news domain, new media is emerging, $48 \%$ were found users of internet for news in 2002 and till 2011 ratio increased up till 61\%. However, findings also revealed that that 'anybody can write an article and publish it' is the main reason for not using the social media as a source for current news. $82.2 \%$ of the non-users do not intend to use social media as the articles are not written by qualified journalists. Another factor is subjectivity in social media news which is based on personal opinion rather news values. But the excessive use of social media which resulted in social media revolution and now research has argued that the Internet can form a "Fifth Estate". The other researches also have documented the increase of social media in news consumption. In May 2010 during UK election 154,342 tweets were sent at 22.77 tweets per second during the third televised leadership debate, leading some call it the UK's first "social media election". This showed the interest of networked individuals and revealed the social media as a significant place which reinforced the hundreds of thousands people and engaged them in political debate. Just before the election, almost half a million people took part in a single Facebook poll on who should make up the next government. The online news sources such as Facebook, Twitter, YouTube and search engines help to evaluate public. Picard describes social media an easy and affordable mean of discussion with larger audience and it also initiate debate on issues which were overlooked by traditional media. Therefore, social media is an opportunity for people to express and connect with others with similar opinion and interests. The major function of news is to orient man and society in an actual world. Earlier investigations found that news mobilized and increased participation through information [6], which results in discussions among people's networks [7], and permitted people to reveal opinion on issues. The previous studies [8] concluded that social media fulfills a need for a fast mode of communication and analyzed four reason of Twitter usage i-e daily chatter, conversation, sharing information and reporting news. The advent of social media has helped the news become a social experience in fresh ways for consumers. People use their social networks and social networking technology to filter, assess, and react to news. New media tools such as Facebook, Twitter, and smartphones have enabled news consumers to be informed in real time about major events and topics of interest.

In recent election of Pakistan in 2013, youth turnout was notable and social media was used to mobilize. As now the youth is heavy user of social media and the news landscape has been changed. Social media broadcast $24 / 7$ breaking news, therefore unsurpassed information is at higher scale. Because of its democratizing nature, users not only can easily, receive but also produce and propagate a piece of information without necessarily providing traceable information. The cycle of transmitted information is re-transmitted again and again through social media. Similarly Kugelman noted that social media is accelerating in Pakistan among youth and used in five ways, it breaks the stories which are disregarded by mainstream traditional media, it mobilize people for campaign, social or political, it promote and coordinate among people to generate debate on issues, it is also used as an activist for social causes and lastly it is used to communicate between public and politics. Despite growth of electronic media in Pakistan and gratifying information needs but social media is taking equal part in this domain [9].

The rapid growths of social media for multiple purposes, particularly for information incite more research to study the factor of these emerging technologies which resulted in its excessive usage for knowledge and information [10]. By assessing the importance of social media, it is needed to know why they use social media and what are the characteristics which give social media an edge over other media.

White, Connaway, Lanclos, Le Cornu and Hood, emphasized to go beyond simple dichotomy of the digital media users and now it is necessary to debate and understand how emerging technologies can support information. Susan Greenfield described the potential of growing new media considered these emerging technologies as an integral part of modern society due to advancement, expansion, accessibility, mobility and current information updates.

In information technology domain, mobility has different parameters and definition. The mobility is paralleled with convenience, i-e availability of social media at all the time. People not only can use social media all the time at any place but also they can ensure their presence on digital debate. They can contribute in information sharing process and disseminate information as well, this leads into social 
capital. The all-time availability and mobility of social media generated a second life (SL), it is virtual world and users have become resident of SL.

The strong and enthusiastically used media in twenty-first century by youth is social media and Pew Internet Project (2016) indicated $89 \%$ youth from 18 to 29 is internet users. This emphasize on the need to research why youth is heavy users of internet and what needs they gratify which result in their preference for social media.

The current study explored how university students (male and female) consume news through social media and in which type of news they prefer social media. Through survey method, the current study intended to answer following research questions:

- RQ1: How has the use of social media in Pakistan affected the news consumption pattern of university students?

- RQ2: How the gender and education has influenced the news consumption through social media?

- RQ3: Do university student feel more or less informed on current issues through social media?

- RQ4: What are the situations which results in excessive use of social media for information?

\section{Theoretical framework}

As Katz and Blumer differentiated active and passive media users and active users select medium and information according to their needs and contribute actively in media routine. Another theory derived from Uses and Gratification is Media system dependency theory which ascertains that the more individual depend on media to fulfill needs, the more media will be important to user. Uses and Gratification (U\&G) identifies how people use media and then selected media to gratify their needs such as information, communication, entertainment, socialization and developing relationships. In addition Media system dependency theory indicated dependency of people on particular medium to gratify needs and this medium become more important to users. This will results in more strong influence and control over user. If individual is using media for information then media will become important source of information for that user. The theoretical framework for the current study lie in U\&G and Media system dependency theory which assumed that university students select media according to their informational needs and this increased their dependency on particular media.

After reviewing the existing literature and stating theoretical frame, following variable are identified.

Usage: Time spent on social media was measured in hours per day, to assess their usage for news seeking through social media.

Social media: Two widely used SNS were selected i-e Facebook and Twitter.

Hard news: Latest and current news of politics, government, judiciary, bureaucracy etc. The categories for hard news were local news, national news, international news and Disaster and Relief Activities News.

Soft news: The news based on human interest or follow up stories, in this entertainment was selected as.

\section{Methodology}

The current descriptive study is based on quantitative methods. The total sample size was 1500 university students (male and female) whereas 1383 participated, which included 833 male and 550 female. Close ended questionnaire was tool of the study. Both male and female university students from 18 to 30 years were selected through multi-stage sampling. Across Pakistan public and private universities from Federal Capital and provincial capital were selected to find out students' preferred source of news. At first stage, list of all universities was obtained through HEC website and at second stage list of HEC recognized (public and private) universities at each province was formulated. At third sate, for researcher convenience, university situated in provincial and federal capital was formed to get data from the selected sample. Other demographics included background, qualification, location, usage patterns, time spent and news seeking interests in soft or hard core information. To measure the data, ordinal scale was used.

\section{Results and Discussion}

In current study 1383 respondents participated, $60.2 \%$ were male whereas 39.8 were female (Figure 1). The results reinforced the fact that still women lack behind in social media usage, although internationally conducted survey in developed countries indicated a higher ratio of female social media users. Some authors detect a gap that sees men's consumption become more intense than women's. An empirical data by Larsen, found both genders seek the acknowledgement through social media. The result, however, explained the tendency of gender inequality which is prevalent in Pakistan where female have limited opportunities (Figure 2).

For the study age was selected from 18 years to 30 years, the findings suggested higher social media usage for news from 21-23 and 24-27 i-e $33.4 \%$ and $33.8 \%$, respectively. Over all from 21 year to 27 years used more social media. YouGov survey advocated Facebook as chief mean of information and new for 18 years to 24 years of people. The Reuters Institute for the Study of Journalism conducted a survey and found $51 \%$ of people accessed social media as main source
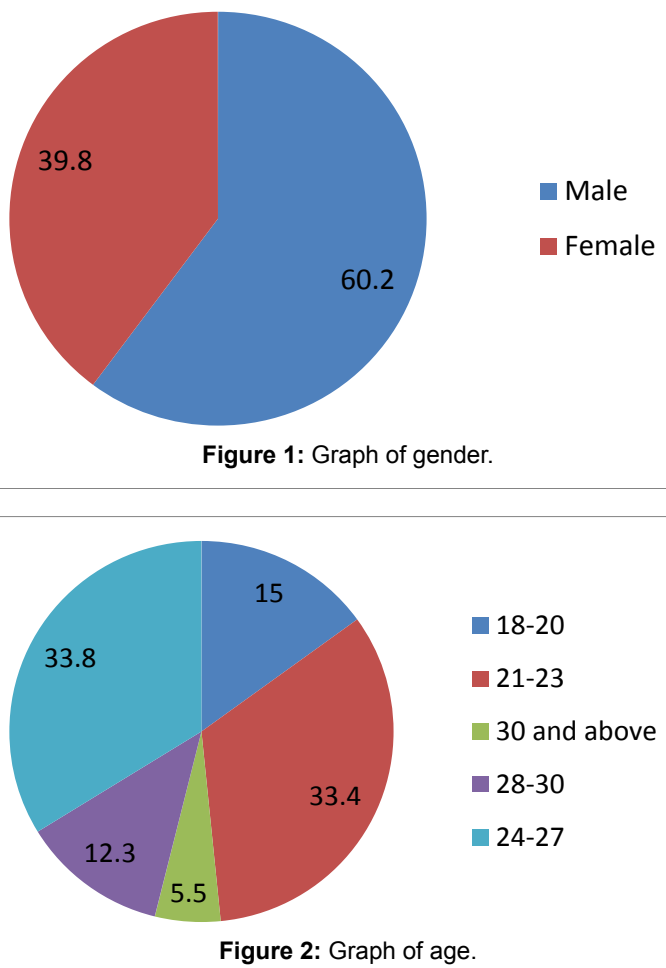
of news. The survey indicated many factor in which usage of smart phones, familiarity with technology and easy accessibility were most prominent. The dominancy of youth on social media was realized and traditional media also adopted e-version for news dissemination. A decade from 2005 to 2015 was considered very crucial, according to Pew Research, in 2005 only 7\% were using social media for news but in 2015, 65\% people were found using social media for news. Platforms such as Facebook and Twitter facilitate the process of discovering news stories, especially in young adults. Two factors were found which impact news consumption pattern in youth, one is age, as people get older they consume more and show greater interest in news the second factor is type of news (Figure 3 ).

The results of age and education correlate with each other. The findings indicated that $58.6 \%$ graduate students used social media for news. The current study intended to examine how university students use social media for news and keep themselves updated with latest happening. Young graduate students and pursuing university education actively participate in social media and they are keener to know and socialize with peer groups. Miller J revealed educated people were more critical in response to what they observe on Facebook feeds. They don't believe that information, therefore education appears to greatly affect respondents' actions in news consumption (Figure 4).

The findings show that using social media has become part and parcel of modern society as this survey found $6.1 \%$ youngsters use more than 4 hours per day and they fall under heavier user category. It highlights the fact that youth is more interesting and keen in using social media. Among the sample, time spent on social media for news found higher and mostly respondents were using social media more than 4 hours. This revealed that for majority of people, social media has become an integral part of their daily life routine especially young people (Figure 5).

The results have shown the rapid inclination toward social media for news as compare to traditional media. A shift from traditional to

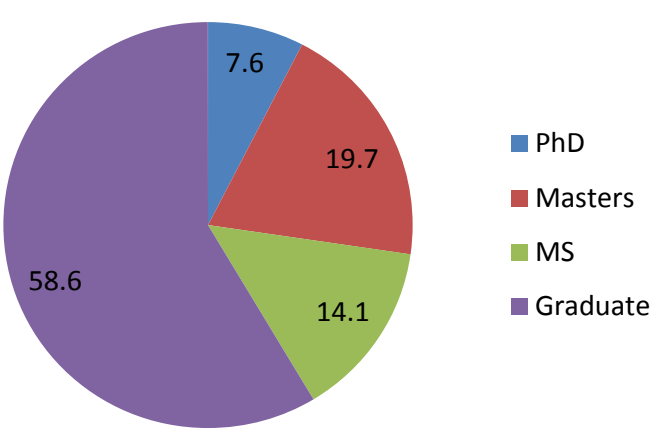

Figure 3: Graph of education.

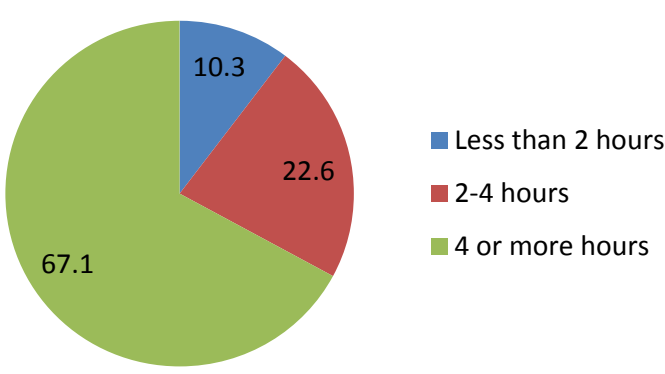

Figure 4: Usage of social media for News. social media was observed [1] but according to Pew Research, TV was the prime source of information and news. The results of this study were consistent with the previously conducted investigations which supported the use of social media for news. The characteristics of social media such as mobility, access and visual sharing played integral part in this shift. Further the active role of audience that they can select news according to their own interest and directly go to that type of news in which they are keen to know. Social media is gradually dominating news domain and this has undermined the role of state fourth pillar. In Pakistan, a visible usage of social media was observed during Election in 2013 when political parties started using social media to mobilize youth for political agenda. A political party "Pakistan Tehreek-eInsaaf" targeted youth as vote bank. Therefore, the utilized social media as youth was heavier user of social media. This shift is also addressed by Andrew and Jason, and indicated generation gap a strong reason. Older generation preferred traditional media due to their lack of familiarity with technology but younger generation is brought up in this technological era. Therefore, youth is resident of this virtual world (Figure 6).

The use of social media for hard and soft news is $14.1 \%$ and $32 \%$ respectively. But a notable percentage of respondents indicated that social media is used for both type of news i-e hard and soft news (53.9\%). The soft news which is based on human interest, for this study soft news was categorized as entertainment news. Now the social media twitter and Facebook both are used by journalists and news organization for breaking, foreign, entertainment, and others type of news. The twitter emerged as a powerful tool in 2009 for dissemination of information. The use of social media among Pakistani youth for news purposes increased at the time of election 2013 when twitter and Facebook became integral tool for political campaign. Somehow this was social media election like UK 2010 election. According to the 2011 State of the News Media Report, all forms of news media suffered audience declines during 2010 with the notable exception of online

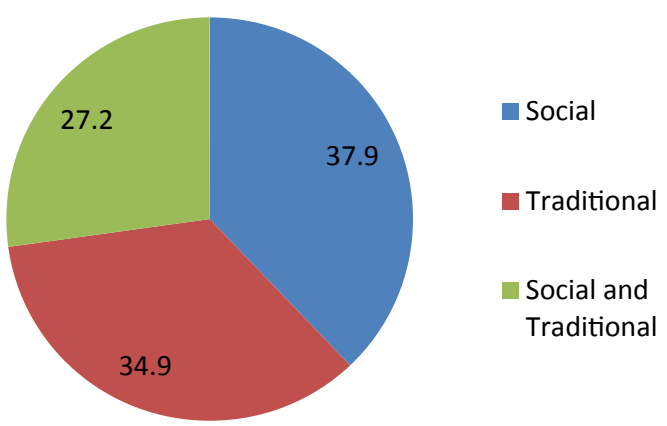

Figure 5: Which media you use for News?

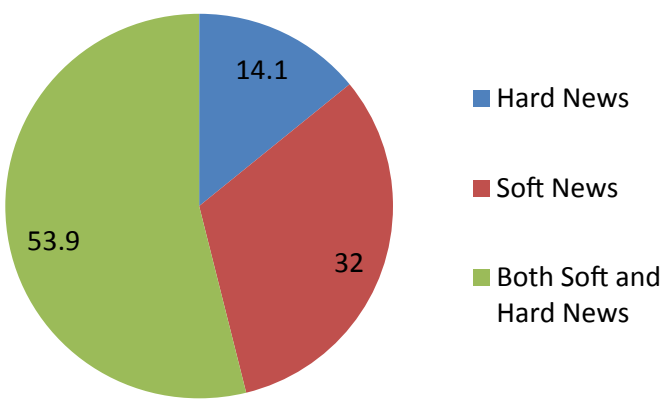

Figure 6: Social media is usage. 
news. Few recent incidents such as ban of Indian movies in Pakistan, Pakistani actors working in India were victimized by extremists parties, statement of filmmakers were followed on social media more than traditional media. All these news were from entertainment category. The "hard news" which is about politics, government, and public affairs remained most top news stories, but now coverage of "soft news" stories-stories about disasters, celebrities, and the like-has increased markedly during the past three decades [11] (Figure 7).

In type of news, the respondents showed that they used social media for local news (31.5\%) and entertainment news (27.3\%), respectively [12]. The third type of news is disaster news which is about any crisis and natural calamity and during this situation, the news are about relief activities. During this current decade, social media played an increasing role in emergencies and disasters. Social media sites rank as the fourth most popular source to access emergency information. They have been used by individuals and communities to warn others of unsafe areas or situations inform friends and family that someone is safe, and raise funds for disaster relief. Literature surrounding the news values model provides an excellent framework to examine characteristics and relevant social media news value. News values have long been discussed in relation to the media as a way to understand what makes certain events newsworthy and others not. The findings describe that news values are also predominant on social media as well. The results have a wide gap between use of social media for local, national and international news [13]. Only $15.9 \%$ are using social media for national news and $2.1 \%$ were consuming international news. Recently US election was the most search international news. Other category of news is entertainment which relate to soft news, as previously it was found that youngsters were using social media more for soft news [14].

\section{Conclusion}

The present study was conducted to measure the use of social media by youth for news acquisition. The findings of study suggested that youth is heavy user of social media and there is shift in usage patterns among youth. Initially they using it for communication and socialization but the revolution in social media gained a place in news domain as well. Several incidents such as youth involvement in Election 2013 in Pakistan was credited to social media, similarly different political parties used social media as news dissemination platform and gathered a huge youth crowd. The results indicated a difference in age and gender is wider in using social media for news. Age differences shrink for Internet-based news but do not disappear. Youth is using social media more than four hours per day therefore they are more engaged and influenced by social media. There is also a major difference in their tendency toward type of news. They consume social media more for soft news as they are more interested in entertainment news.

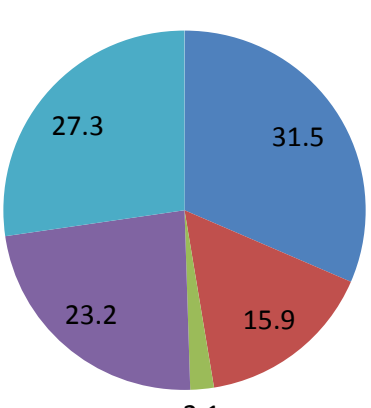

2.1

Figure 7: Type of News
Whereas in type of news, they showed their interest in local news. The proximity is one of the major elements of news; people take interest in issues which are directly related with them. Local issues influence daily routine and have huge impact of people living in surroundings; it is also reiterated by the findings. Social networks such as Twitter and Facebook play a leading role in the spreading of news stories. The use of social media increased for news acquisition during crisis situation.

\section{Recommendation for Future Study}

It is evident that media research particularly in social media domain will continue and explored multiple related factors. The future study can be conducted to measure the frequency of social media use for each news and to what extent social media inform users than traditional media in real time experience. The other most important area is to explore the role of social media as Fifth-state pillar in Pakistan as numerous events has reinforced the contribution of social media in generating debate on issues which have been over-looked by traditional media. Future investigations should be carried out to ascertain if people who depend on social media for their news are informed on current events reported in the mainstream press. Further, future study can be conducted to compare trending of news topics on social media websites and what traditional news outlets are reporting should be studied.

\section{References}

1. Harper RA (2010) The social media revolution: exploring the impact on journalism and news media organizations. ResearchGate

2. Newman N, Dutton WH, Blank G (2012) Social media in the changing ecology of news: The fourth and fifth estates in Britain. International Journal of Internet Science 7: 6-22

3. Lenhart A, Madden M, Smith A, Purcell K, Zickuhr K et al (2011) Teens, Kindness and Cruelty on Social Network Sites: How American Teens Navigate the New World of digital citizenship. Pew Research Center Internet and Technology.

4. Holcomb JB, Del Junco DJ, Fox EE, Wade CE, Cohen MJ, et al. (2013) The prospective, observational, multicenter, major trauma transfusion (PROMMTT) study: comparative effectiveness of a time-varying treatment with competing risks. JAMA Surgery 148: 127-136

5. Hargittai E (2007) Whose space? Differences among users and non-users of social network sites. Journal of Computer-Mediated Communication 13: 276-297.

6. Lemert JB (1992) Effective public opinion. Public opinion, the press, and public policy 41-61.

7. Shah DV, Cho J, Eveland WP, Kwak N (2005) Information and expression in a digital age modeling Internet effects on civic participation. Communication Research 32: 531-565.

8. Java A, Song X, Finin T, Tseng B (2007) Why we twitter: understanding microblogging usage and communities. In Proceedings of the 9th WEDKDD and 1st SNA-KDD 2007 workshop on Web mining and social network analysis 56-65.

9. Eijaz A (2013) Impact of New Media on Dynamics of Pakistan Politics. Journal of Political Studies 20: 113

10. Hyldegård J (2014) Young learners' use of social media for information seeking: Exploring core lis journals from 2010-2014. LIBRES: Library and Information Science Research Electronic Journal 24: 108-117.

11. Patterson TE (2000) The United States: News in a free-marke society. Democracy and the media: A Comparative Perspective 241-265.

12. Barbier G, Feng Z, Gundecha P, Liu H (2013) Provenance data in social media. Synthesis Lectures on Data Mining and Knowledge Discovery 4: 1-84.

13. Gundecha P, Feng Z, Liu H (2013) Seeking provenance of information using social media. In Proceedings of the 22nd ACM international conference on Information \& Knowledge Management 1691-1696.

14. Connaway LS, Hood EM, Lanclos D, White D, Le Cornu A (2013) Usercentered decision making: a new model for developing academic library services and systems. IFLA Journal 39: 20-29. 